\title{
Ciências Sociais, religião e periferia: lugares e olhares em Roger Bastide
}

Places and glances at Roger Bastide: Social Sciences, religion and periphery

\section{Moacir Carvalho}

Resumo: Pretende-se nesse artigo discutir as relações entre a formação da Sociologia e Antropologia da Religião brasileira, considerando-se que a condição de subalternidade tanto econômica quanto acadêmica em relação ao centro do capitalismo mundial entre as décadas de 1930-1950, condicionaria nossa localização mediante um tipo de hierarquização disciplinar, temática e teórica que, se era devedora do que se dava no centro, não reproduziria cegamente o mesmo padrão. Partindo-se da ideia de modernidades múltiplas de Eisenstadt, procura-se argumentar que a especificidade de nossa condição nacional enquanto ex colônia impunha desafios distintos aos intelectuais nativos, de forma que a cultura popular adquiriria um significado central para a própria autodefinição do acadêmico brasileiro que se encontrava na origem de sua construção durante os anos 1930-1950. Época da conformação de grande parte dos institutos de ciências sociais entre nós. Para a análise, se tomará o trabalho de Roger Bastide como emblemático das ambiguidades vividas por essa geração de intelectuais. Embora não se tratando de um brasileiro, se argumentará que a figura de Bastide seria especialmente estratégica não só para se pensar alguns dos dilemas vividos pelos intelectuais nacionais, como também os percursos da Sociologia da Religião nacional.

Palavras-chave: Ciências sociais brasileiras, religião periferia, Roger Bastide

Abstract: This article aims to debate the relationship between the formation of Sociology and Anthropology of Religion in Brazil. I argument that the

1Doutorando em Sociologia pela Universidade de Brasília. E-mail: moacir.carvalho@gmail.com

Latitude, Vol. 8, no 2, pp. 395-425, 2014

DOI: https://doi.org/10.28998/2179-5428.20140207 
condition of economic and academic subalternity in relation to the center of the global capitalism between 1930's and 1950's would limit our social position expressed in a kind of disciplinary, thematic and theoretical ranking. This hierarchy would be indebted to what emanated from the center, yet it did not reproduce itself under the same social pattern. From the idea of multiple modernities of Eisenstadt, I argue that the specificity of our brazilian national condition as a former colony imposed distinct challenges to native intellectuals. One of them is that the popular culture acquired a central meaning for the self-definition of lot of Brazilian intellectuals once this label was the source of its position during the years 1930-1950. In this period, a large part of the institutes of social sciences among us emerged. In order to analyze this issue, the work of Roger Bastide became a reference to represent the ambiguity experienced by that generation of intellectuals. Even though Bastide was not Brazilian, he is especially strategic not only to think some of the dilemmas faced by national intellectuals, but also to analyze the paths of Sociology of Religion in Brazil.

Keywords: Brazilian Social Sciences, religion, periphery, Roger Bastide

\section{Introdução}

Salta aos olhos a presença, ou mesmo fortalecimento do fenômeno religioso nas últimas décadas, isso, num momento em que pareceria haver uma generalização de aspirações por mais consumo, entretenimentos pagos, maior individualismo, mobilidade social, acesso às inovações tecnológicas. Enfim, aspirações que para se realizarem dependeriam, a princípio, de um posicionamento no mundo que considerasse a coordenação entre fins e meios de uma maneira distinta, ou mesmo contraposta a certos imperativos religiosos, ou àqueles típicos da sociedade mercantil-escravocrata que nos deu origem. E, se até a década de 1950 a Sociologia da Religião, pelo ao menos na Europa e Estados Unidos era tida como área de menor importância, no Brasil as expressões religiosas vêm recebendo um tratamento intenso e complexo por parte das ciências humanas já há bastante tempo.

Explorar-se-á aqui a ideia, defendida por autores como Eisenstadt, Ortiz, Giumbelli, Canclini, Asad, entre outros, de que os programas 
culturais implicados nos processos de modernização não só não seriam idênticos, podendo-se em muitos casos se rejeitar as prerrogativas exclusivamente ocidentalizantes, como modernidades e modernizações estariam em um movimento nunca acabado. Daí ser possível se abandonar o espanto diante do fato que a esfera religiosa não só não encolheu, principalmente nos países periféricos pós colonizados, mas se diversificou, produziu inovações, aumentou a intensidade de suas atividades e exigiu novos padrões de integração e compromissos. Ao mesmo tempo, haveria aqui uma relação entre a herança colonial e a especialização mundial do campo intelectual que precisa ser levada em consideração para se compreender o posicionamento de alguns dos autores que se interessaram pela cultura popular entre nós durante o século XX. É preciso lembrar que então ocorreria no país em um curto período²: a invenção nacional de duas religiões importantíssimas, o Kardecismo e a Umbanda; a diversificação protestante; a reorganização contra-ofensiva do catolicismo mediante romanização e restauração; a reelaboração do Candomblé, assim como de uma série de outras práticas afro-brasileiras país afora: de caso de polícia à componente dentre as mais importantes da cultura popular. Isso para não falar das impactantes transformações e recriações por que passou o pentecostalismo entre o final do século XX e o início do XXI.

O período que vai de 1890 a 1940-1950, pelo ao menos, teria sido um dos mais dinâmicos e interessantes sob o ponto de vista religioso. Todavia, período em que todo o bloco ocidental de poder dominante em que vicejava a profissionalização acadêmica nas humanidades apostava numa

2 Contexto em que não só surgiria a Umbanda, reivindicadora do título de única religião verdadeira e autenticamente nacional, saída do Rio de Janeiro, como também se definiria a supremacia nagô dos Candomblés baianos em Salvador enquanto expressão popular e mediante atividade combinada entre lideranças nativas e intelectuais, reivindicação de pureza ritual superior e ancestralidade. Tripartição essa - entre mercado, Estado e cultura - que teria servido ao mesmo tempo como delimitadora e coordenadora das trocas em que autenticidade e inautenticidade-degradação da expressão religiosa seriam polos opositivos fundados em critérios que, ampliando-se para além das fronteiras da comunidade - templo, tenda, casa, igreja, centro ou terreiro - se teriam montado no circuito mais ampliado do território nacional, principalmente nas maiores cidades.

Latitude, Vol. 8, no 2, pp. 395-425, 2014 


\section{Ciências Sociais, religião e periferia: lugares e olhares em Roger Bastide}

ininterrupta perda de força da religião. Ou seja, havia uma diferença nos movimentos entre "centro" e "periferia", também sob o ponto de vista da formação e interesses dos respectivos intelectuais espalhados ao redor do globo, e que precisaria ser considerada:

[...] As 'regras do método' devem se acomodar ao movimento de regionalização no qual temas e enfoques particulares são desenvolvidos. Isso fica claro quando se observa os objetos privilegiados pelos pesquisadores. Enquanto na Europa e nos Estados Unidos, a Sociologia se ocupa de assuntos como divisão do trabalho, urbanização, industrialização, metrópole, racionalização, na América Latina nos encontramos diante de questões como mestiçagem, oligarquias, religiosidade popular, mundo rural. Se para os europeus e norte americanos $\mathrm{o}$ fundamental foi explicar a modernidade, no caso latino americano era a sua ausência, ou melhor, as dificuldades para construíla, que chamava a atenção. (ORTIZ, 2002, p. 21)

Como descreve Ortiz, coordenava-se no interior das aspirações universalistas das ciências sociais uma distribuição de interesses através dos territórios do globo que então se abriam à pesquisa. Frente às coisas incríveis que podiam ver, fazer e falar os antropólogos, bem como sociólogos e cientistas políticos, estipulava-se o que era do interesse dos pesquisadores trabalhando no centro, e o que valeria se procurar nas regiões periféricas do capitalismo mundial. Muitos destes pesquisadores lidavam com os avanços técnico-científicos, as transformações econômicas, movimentos sociais, expressões culturais leigas, arte, intelectuais e literatura, Estado, e os dilemas da geopolítica mundial, no que também vigorava uma segmentação da população entre dois blocos de poder, cada qual com seus respectivos centros mais poderosos franqueando para si a tarefa tutelar frente às nações subalternas. Daí que se o problema da cultura dependeu dos processos mundialmente generalizados de formação das sociedades nacionais entre os séculos XIX e XX, tal circunstância levou a caminhos imprevistos sob o ponto de vista da importância que práticas 
culturais como a religião viriam a ter no interior da tensão entre tradicionalização e modernização. Nos países centrais o tema da cultura popular tinha sido dominado pelos folcloristas românticos durante o século XIX. E dificilmente um autor como Weber entenderia seu trabalho como sugestão de agenda pesquisatória futura sobre religiões nas regiões mais desenvolvidas da Europa. Nesse contexto, a religião, ao menos a própria, não era coisa particularmente valorizada, restringindo-se por seu turno o interesse pelo tema aos antropólogos que buscavam preferencialmente os recantos cada vez mais raros do mundo, dos quais voltariam com suas malas cheias de novidades; aos sociólogos por acaso interessados, restaria resignar-se a uma condição de subalternidade no campo profissional se viessem a permanecer trabalhando em seus países de origem com temas como esse - não me parecendo coincidência que o sociólogo Roger Bastide de que mais abaixo tratarei, tenha sido o cientista social que provavelmente mais tempo residiu no Brasil dentre os que aqui chegaram através da missão francesa de professores que vieram para a USP.

Dessa forma, se tais circunstâncias originárias tinham um peso considerável na distribuição social de prestígio, recursos e temas ao redor do mundo, só em parte elas se reproduziriam nas regiões pós-colonizadas. Assim, o Brasil que no espaço entre os anos 1890 e 1950 vivia o dilema entre ser o mesmo ou o outro do ocidente se colocaria também no que toca a formação das ciências sociais, justamente, nesse interstício. Tornando-se lugar interessante para se estudar as religiões, principalmente para os pesquisadores estrangeiros que para aqui vieram; era também um espaço em que se lutava violentamente para se superar o "obscurantismo religioso" que, segundo muitos ideólogos, dominaria a mentalidade principalmente de negros e mestiços. E, pergunta-se: seria apenas por uma fidelidade às fontes que nenhuma das grandes obras que trataram da formação brasileira e foram produzidas entre as décadas de 1930 e 1940 por brasileiros, consideraria a religião como tema central ou decisivo? Em parte a resposta a essa pergunta deve mesmo ser positiva. Todavia, observandose algumas das pesquisas que relacionavam raça, cor, etnia e religião em Salvador, primeiramente com Nina Rodrigues e posteriormente entre os anos 1930-50 com Arthur Ramos seguindo-se da entrada dos pesquisadores estrangeiros por todo o país, parece que essa versão sobre o lugar ocupado pelo tema religioso exige alguns questionamentos.

Latitude, Vol. 8, no 2, pp. 395-425, 2014 


\section{Ciências Sociais, religião e periferia: lugares e olhares em Roger Bastide}

Para que as pesquisas sobre religião pudessem finalmente começar a enfrentar os dilemas de uma cultura popular em uma nação pós-colonial e escravocrata, era necessário primeiramente que o foco se deslocasse do catolicismo para as expressões originadas entre os segmentos de cor, principalmente as afro-brasileiras. Ou seja, que se deixasse, também sob o ponto de vista religioso, de enxergar o Brasil como extensão lusitana. Daí só anos após a sua morte é que Nina Rodrigues ganharia a importância que ganhou, pois, mesmo sendo portador de um título valorizado como o de médico, os resultados de suas pesquisas sobre religião não despertariam maiores interesses entre a sua morte e a década de 1930, ou seja, passadas quase duas décadas de seu falecimento. Isso só mudaria pelas mãos de um discípulo seu. Antes disso, possivelmente apenas Manoel Querino teria recorrido ao seu trabalho, mas seria de fato seu discípulo Arthur Ramos aquele que resgataria de forma mais sistemática sua obra.

Como é sabido, vários intelectuais após 1920 passariam a elaborar o país através de aspectos da cultura a serem lidos por critérios que englobavam uma estética e uma poética que se convencionou chamar de modernismo. Todavia, embora não sendo possível se alongar nesse ponto, muitas vezes tal sensibilidade pareceu aproximar-se mais do romantismo do que seus defensores gostariam de admitir. O romantismo, como afirma Silvio Romero, se disseminaria e popularizaria no Brasil para além dos círculos especializados ${ }^{3}$, exigindo-se do intelectual certa superação da repulsa ao popular. Ao mesmo tempo, Silvio Romero foi um dos primeiros a falar da necessidade de estudos sobre as populações de origem africana no Brasil que equilibrassem a exclusiva valorização do indígena. Em "Estudos sobre a poesia popular do Brasil" diz ele:

É uma vergonha para a ciência do Brasil que nada tenhamos consagrado de nossos trabalhos ao estudo das línguas e das religiões africanas [...] Nós que temos o material em casa, que temos a África em nossas cozinhas, como a América em nossas selvas, e a Europa em nossos salões, nada havemos produzido nesse sentido! [...] O negro não é só uma

\footnotetext{
${ }^{3}$ Ver "História da Literatura Brasileira" de Silvio Romero.
} 
máquina econômica; ele é antes de tudo, e malgrado sua ignorância, um objeto de ciência. (ROMERO, 1888).

Nina Rodrigues foi o primeiro a responder o chamado; veja-se o que cheio de sentimentalismo escreve o grave cientista sobre uma visita ao terreiro do Gantois: "O sítio ermo e recôndito, as horas mortas da noite, a monotonia grave e triste da música rude e da melopéia africana, o caráter extravagante e estranho das danças religiosas, tudo concorria ali para dar ao conjunto um cunho de poesia selvagem e misteriosa que deveria falar profundamente ao espírito acanhado e inculto de uma raça supersticiosa em extremo" (RODRIGUES, 1935, p. 64). Permitam-me a pergunta: A quem tudo aquilo falava profundamente? A quem tudo era misterioso, estranho e extravagante? Aspectos que teriam inspirado as ideologias nacionais do século XIX ${ }^{4}$, e que só puderam ser plenamente elaborados no interior de um espírito romântico e através de um tipo específico de valorização da autenticidade do popular que vinha sendo gestado de dentro das expectativas dos intelectuais ${ }^{5}$. E mais uma vez Ortiz:

Na América Latina, o interesse pela cultura popular é semelhante ao que ocorre nos países periféricos europeus. A ausência de modernidade, ou seja, sua realização 'incompleta', implica o corolário oposto, a riqueza das tradições populares (o que é visto como um entrave à modernização pelas elites

4 Manuel de Araújo Porto-Alegre (1806-1879) foi um escritor romântico que realizou sessões de psicografia em Paris e escreveu a peça teatral "Os Voluntários da Pátria". E até hoje Castro Alves, por exemplo, é especialmente considerado entre os espíritas. E o que dizer das infinitas referências, reverências e psicografias atribuídas a Victor Hugo?

${ }^{5}$ Mas, busca de autenticidade que pouco a pouco se cruzaria com o influxo modernista da década de 1920, ou melhor, se aprofundaria até o enraizamento na própria sensibilidade dos segmentos populares - pois a poesia romântica na música popular não cativaria apenas um público letrado, sendo por vezes rejeitada por esse público -, estendendo-se para uma produção e clientela cultural que também, mas não apenas, se interessava por religião.

Latitude, Vol. 8, nํㅡ 2, pp. 395-425, 2014 


\title{
Ciências Sociais, religião e periferia: lugares e olhares em Roger Bastide
}

\author{
dominantes) [...] As expressões culturais \\ tradicionais constituem assim, referência obrigatória \\ [...] Orientando o debate numa direção inteiramente \\ distinta, também nos Estados Unidos, onde o \\ conceito de cultura popular praticamente se \\ identifica ao de 'cultura de massa', isto é, aos bens \\ culturais produzidos industrialmente. (ORTIZ, \\ 2002, p. 22)
}

Nascido no contexto imperialista das nações capitalistas liberais centrais, um interesse predominantemente antropológico se confundiria com a própria simbolização do mapa mundi entre os séculos XIX e XX. Ao mesmo tempo em que se temia a desagregação das expressões culturais ainda sobreviventes nas colônias e ex-colônias em decorrência do próprio processo que possibilitava e demandava seu registro, gerava-se uma localização, ainda que temporária, à Antropologia como especialidade. Destarte, os intelectuais nativos das regiões periféricas passavam a habitar uma zona cruzada de interesses e possibilidades que os favorecia, mas, ao mesmo tempo, retirava parte do seu poder. E assim seria, o interesse pela unidade e singularidade cultural marcaria grande parte da produção desse período no Brasil e, nesse caso, a produção da alteridade constituía-se dentro da própria relação entre o ocidente desenvolvido e o resto do mundo em desagregação, mas, ainda ricamente dotado de "cultura". Simbolização do espaço e divisão entre especialidades que não só marcariam a produção das ciências sociais mundiais, como viriam se inserir na lógica de pensamento e nas pautas de trabalho dos próprios pesquisadores nativos das regiões pós-colonizadas em que três dimensões começavam a se distinguir, superando-se o estatuto privilegiado da arte como cultura verdadeira: a alta cultura, a cultura popular, e a cultura de massa. Sendo que no Brasil, ao contrário dos Estados Unidos, demoraria ainda um pouco para que a cultura de massa entrasse seriamente na pauta dos cientistas sociais. Não é por acaso a observação de Ruth Landes ao perceber que os intelectuais brasileiros não considerariam que os americanos, fortemente identificados a um sentido massivo e laboral do popular, possuíssem cultura, havendo apenas uma sociedade que dividia seu tempo entre trabalhar, gastar, comer e descansar. 


\section{Diversificação intelectual, profissionalização e o popular nacional}

De fato, nenhuma das principais obras de síntese sobre a formação nacional conferiria grande importância à religião. Todavia, na esteira do que se fazia na época, tornava-se um desafio produzir-se uma interpretação do tema religioso que fornecesse um sentido de continuidade com a formação da sociedade brasileira. Por outro lado, não sendo mais suficiente a ideia de uma nação católica em relação a qual gravitariam determinadas expressões secundárias, tal síntese precisaria incorporar influências e matrizes espirituais diversas em um conjunto minimamente coerente. Destarte, uma das tarefas a que se propuseram alguns pesquisadores, principalmente, para os interesses desse artigo, os localizados entre o Rio de Janeiro, São Paulo e Salvador, e que entre as décadas de 1930 e 1950 viviam o entusiasmo e a inquietação despertados pelo modernismo, bem como por obras como Casa grande e Senzala, Raízes do Brasil e Formação do Brasil Contemporâneo, teria sido a de fornecer uma visão de conjunto da cultura nacional que extraísse da religião algum ingrediente único e verdadeiramente expressivo da nossa civilização.

Certamente que sincretismo foi o termo comum no qual se aglutinariam vários dos trabalhos dessa época, mas também, seria de grande alcance teórico, metodológico e empírico os trabalhos, principalmente os estrangeiros, que pretendiam relacionar contatos interétnicos, religião, sociedade e cultura. Nesse ponto o tema religioso faria escola, merecendo especial interesse, principalmente quando combinado as discussões sobre cor, raça e etnia, no interior dos respectivos dilemas locais em que se tensionavam tradição e modernidade. Força e fraqueza dos trabalhos sobre religião nessas regiões, o que seria importante para o caso brasileiro em que, não só o tema religioso começava a merecer o interesse nativo já desde Raymundo Nina Rodrigues, assim como dito, ganharia a atenção de diversos pesquisadores estrangeiros, aumentando-se ainda mais o prestígio do tema após as décadas de 1930-1940 e já no ambiente de debate estabelecido por "Casa Grande e Senzala" e "Sobrados e Mucambos". Dentre os principais nomes pode-se citar: Roger Bastide, Melville Herskovits, Frazier, Donald Pierson, Ruth Landes e Pierre Verger, entre os mais importantes, sendo que à exceção de Bastide, os demais aqui elencados concentrariam suas pesquisas em Salvador - e mesmo Bastide concentrou sua etnografia na Cidade da Bahia, também acolhendo e atualizando a ideia de superioridade nagô. 


\section{Ciências Sociais, religião e periferia: lugares e olhares em Roger Bastide}

Seria nesse contexto que o tema do sincretismo se tornaria não só importante, mas aquela espécie de categoria capaz de coordenar em um só termo mito, história e utopia para toda uma geração, passando mediante esse consenso prévio e quase irrefletido a falar de algo que ultrapassaria os limites internos à atividade especializada dos intelectuais e pesquisadores. Seja como for, qualquer ambição de síntese seria especialmente dificultada diante de um universo multipolarizado e em transformação. Melhor: diante de um universo no qual se dava uma profusão de oficiantes religiosos informais e por conta própria, já estava em andamento uma orientação de valorização do modelo denominacional, tanto acadêmica quanto nativa, mas, orientação que se mostraria insuficiente para acompanhar um universo extremamente variado e em transformação como era o mágicoreligioso brasileiro, cheio de oficiantes informais e por conta própria. Tal orientação estava em andamento já desde 1910, mas, principalmente, entre as décadas de 1920 e 1940 entre as religiosidades populares. Ao mesmo tempo, ela dava continuidade aos esforços teóricos dos autores fundadores da Sociologia.

Também, diante dos avanços nas pesquisas, bem como pela adoção de perspectivas teóricas focadas no problema do poder e do conflito, vai se tornando inviável se falar de uma democracia racial brasileira. Nesse aspecto foi importantíssimo o projeto UNESCO no Brasil, questionando-se também daí em diante a existência de um padrão de equivalências étnico-raciais no território absolutamente distinto do que ocorreria com todos os outros povos do planeta. Com isso, ultrapassava-se aquele ponto limítrofe dos trabalhos nacionais sobre religião até a década de 1940. Trabalhos que, se tinham ambições em termos de síntese, estavam ao mesmo tempo posicionados no interior da relação entre a produção da pesquisa, a formação nacional, e os marcos teórico-metodológicos à disposição num contexto de quase inexistência de centros acadêmicos especializados, o que também significava uma circunstância de desconhecimento mútuo entre pesquisadores, com todas as insuficiências decorrentes de levantamentos de campo fragmentados, ou pouco sistemáticos, por exemplo. Nesse sentido, a vinda de pesquisadores estrangeiros para o Brasil entre as décadas de 1930-1950 também significou um segundo desafio, após as grandes obras de síntese nacionais, sobre o que se poderia produzir em termos de cultura popular e, em especial, sobre religião e relações raciais num país que seria recorrentemente descrito 
como que combinando aspirações por modernização e modos de viver e interpretar herdados da colonização. Daí a centralidade em se considerar a forma como os pesquisadores do período e posterior enfrentariam questões como as seguintes:

A cultura e a estrutura familiar negras seriam o resultado da escravidão e mais tarde a adaptação à pobreza? Ou seriam o resultado de africanismos, de formas tradicionais africanas de vida e de cultura adaptadas ao novo mundo? Por trás dessas duas perguntas existem duas diferentes perspectivas de luta antirracista: o antropólogo (Herskovits) e o linguista (Turner) destacando as diferenças culturais e tomando em consideração a sua capacidade de resistência, contra o sociólogo (Frazier) enfatizando a universalidade da condição humana e o caráter intrinsecamente mutável de todas as formas culturais e sociais. A diversidade cultural contra a universalidade da condição humana; a pessoa negra merecendo respeito por sua cultura e personalidade serem intrinsecamente diferentes, ou, ao contrário, por ser um humano como qualquer outro. (SANSONE, 2001, p. 10)

As observações de Sansone bem poderiam ser interseccionadas a uma polarização correlata, a qual se coloca a respeito da velha polêmica entre cultura popular e erudita, com isso melhor delimitando-se a triangulação entre culto, popular e massivo. Segundo Chartier as inúmeras definições da cultura popular poderiam ser sintetizadas em basicamente dois modelos:

O primeiro, no intuito de abolir toda forma de etnocentrismo cultural, concebe a cultura popular como um sistema simbólico coerente e autônomo que funciona segundo uma lógica absolutamente alheia e irredutível à cultura letrada. $\mathrm{O}$ segundo, preocupado em lembrar a existência das relações de dominação que organizam o mundo social, percebe

Latitude, Vol. 8, nํㅡ 2, pp. 395-425, 2014 


\section{Ciências Sociais, religião e periferia: lugares e olhares em Roger Bastide}

a cultura popular em suas dependência e carências em relação à cultura dos dominantes. (CHARTIER, 1995, p. 180)

Considerando-se as posições acima, embora complementares, ou mesmo muito semelhantes no que toca ao problema crucial de se pensar a cultura popular como dependente ou autônoma em relação a um conjunto de poderes e símbolos que não lhes seriam específicos, precisa-se apontar uma diferença. No segundo caso, fica sugerida a identificação entre "dependência" e certa carência, de toda sorte, unilateral. Ou seja, o termo dependência perde aqui em capacidade descritiva; uma vez que em si mesmo ele não diz nada a respeito da configuração que se quer descrever, não faz muito sentido a suposição de que a preocupação em se identificar relações de poder assimétricas implicaria necessariamente em se assumir haver uma insuficiência simbólica do dominado frente ao dominante Norbert Elias fala de dependências, ou interdependências entre adversários por exemplo. Ao mesmo tempo em que as próprias dimensões "popular" e "letrada" não só aparecem aí muito mais rigidamente polarizadas do que em realidade considero que o são (BURKE, CANCLINI, MARTINBARBERO), parece que Chartier nos oferece uma síntese bem melhor ajustada à realidade europeia que a dos exemplos de sociedades pós colonizadas que tenho conhecimento. De toda sorte, provavelmente a rigidez desse esquema traria dificuldades também para se compreender a realidade europeia, ao menos a do último século.

É talvez da maneira como, teoricamente, se polarizaram esses extremos ideais, que advenham algumas das confusões quando se fala de codependências entre popular e erudito. Pela própria natureza vitalmente política do tema, torna-se particularmente difícil a tarefa de distinguir a necessidade de se levar em consideração as relações assimétricas de poder, de uma suposta inferioridade congênita ao fato de se ser designado como popular. Ou seja, será que a afirmação de que a cultura popular seria inferior ou carente seria o melhor ponto de parida para se enfrentar os dilemas a respeito dos processos de nacionalização da cultura em que popular e elite tiveram de se redefinir? Não seria o caso de se considerar, ao contrário, que indivíduos e grupos que, dotados de determinadas formas de fazer e crer, uma vez entrando em relações nas quais ocupam uma posição de subalternidade, também sofreriam o fato incontornável de ter 
que renegociar e, portanto, resignificar ou, no limite, ver serem destruídas e cair no esquecimento formas, artefatos e estilos de vida? Seja como for, que tal negociação, quando possível, precisa ser realizada diante de circunstâncias de inferiorização relativa, hierarquização essa que é ao mesmo tempo constituinte e constituída pela singularidade, de fato assimétrica, mas sempre variável e em mutação dos encontros. Daí vai uma grande diferença para a formulação de Sansone, a qual não só me pareceria mais esclarecedora de uma realidade pós-colonial, e não só a brasileira, como oferece elementos dinâmicos para se pensar a sua relação com as pressões universalistas ligadas a própria realidade do tipo de contato descrito. O que se pretende nesse artigo é explorar, justamente, que a localização entre os polos erudito e popular, como também o massivo quando for o caso, para utilizar uma classificação de Cancline, não só estariam em constante estado de reformulação, como, no caso de boa parte das nações pós colonizadas, as posições ocupadas e defendidas pelos intelectuais ajudariam em muito a se entender as configurações de poder vividas nesses países.

Assim, a religião tornar-se-ia a partir da década de 1930 parte fundamental do esforço de compreensão realizado pelos intelectuais sobre a condição dos imensos magotes de pessoas de cor que se ajuntavam em condições diferencialmente subalternas, em cidades igualmente diferenciadas quanto as relações entre dominantes e dominados no contexto nacional, no que se buscou formular de maneira não folclorizada ou evolucionista a relação entre tradição, modernização e cultura popular. Entre os pesquisadores que aqui chegaram, na esteira do que vinha sendo feito por Franz Boas desde a década de 1910, haveria então, segundo Sansone, dois extremos: um sintetizado na figura de Frazier, e outro na de Herskovits. Todavia, se é correto se pensar que a produção discursiva dos intelectuais brasileiros entre as décadas de 1930 e 1960, principalmente entre 1940 e 1950 propugnasse uma ação tutelar destes frente às religiões populares, ação essa que tentava superar, um tanto contraditoriamente, a circunstância de inferiorização frente às representações cultas e católicas do nacional a que estariam relegadas as práticas e saberes populares, não deixa de ser correto, como já se indicou mais acima, que os próprios intelectuais, artistas e escritores encontrariam nas religiões afro-brasileiras um espaço e prestígio e fonte de inspiração, sendo que muitos deles viriam 
Ciências Sociais, religião e periferia: lugares e olhares em Roger Bastide

a ser reconhecidos enquanto interlocutores oficiais dessas expressões. Passo agora a discutir alguns aspectos da oba de Roger Bastide.

\section{Bastide e a religião: umbanda, candomblé, macumba e sincretismo}

Um dos autores que talvez mais ajude na compreensão desses dilemas seja Roger Bastide enquanto alguém que viveu parte de sua trajetória nos interstícios. Sociólogo francês que morou e trabalhou durante dezessete anos no Brasil, colocava-se entre as premências intelectuais nacionais, locais e internacionais que se cruzavam e confundiam. Sociólogo de tradição aproximada à Antropologia, com interesses em Psicanálise e crítica de arte, no entre de uma economia simbólica em que mesclava-se sua condição de europeu vivendo numa ex colônia, justamente num campo disputado não só por observadores nativos, mas, também pelos antropólogos americanos que visitariam o país entre as décadas de 1930 e 1940, e no que se contribuiria entre outras coisas para a escolha da Bahia para a realização do projeto UNESCO na década de 1950. Ao mesmo tempo, tema que se tornaria fundamental às narrativas sobre cultura popular, a composição do nacional e do mercado turístico ao longo do século, e que colocaria a Bahia no centro das ciências da religião nacionais, principalmente quando a isso combinavam-se os temas da raça, cor e etnia. Muito embora não tendo superado aquela difícil oposição sintetizada mais acima por Sansone, Roger Bastide pode ser considerado o autor que definiria o marco fundador de uma agenda de pesquisas sobre religião entre nós. Mas ele não estipulou um sistema precisamente recortado, gerando ao invés uma dupla, ou tripla solução. Esta, tantas vezes contraditória ao desafio de se produzir uma síntese suficientemente abrangente que coordenasse os vários caminhos da religiosidade nacional, Roger Bastide simboliza um ponto riquíssimo de intersecção na história das ciências sociais nacionais.

Interessando-se pelas diversas expressões religiosas afro-brasileiras espalhadas pelo território, Bastide inauguraria entre nós a discussão sobre religião sob o ponto de vista da memória, em que pese o dilema entre universal e particular, e onde combinavam-se Sociologia, Antropologia e Psicanálise. Justamente por isso torna-se o autor excelente oportunidade para pensar as dificuldades que o tema, naquelas circunstâncias, proporcionava. Por um lado, ele proporia uma interpretação 
marcadamente processual, ainda que buscando fontes estruturantes da vida exteriores ao processo religioso, em que a religião responderia mais ou mentos automaticamente e nem sempre com sucesso às imposições da sociedade classista modernizadora, por outro, buscaria no passado, enquanto tradição, a condição de preservação da memória e das virtudes civilizacionais específicas a cada povo que habitasse o planeta:

Ora, o Candomblé está baseado no espírito comunitário e não no individualismo, numa economia capitalista de lucro, no sucesso individual como consequência do cumprimento regular dos deveres religiosos, e não como fruto do esforço tenaz do trabalho profissional, da vontade de subir. As seitas africanas não podem, pois, se reconstituir num meio tão hostil, mesmo nas zonas intersticiais da plebe abandonada dos subúrbios ou apenas tomando a forma do espiritismo de Umbanda, que é [...] a única forma possível de adaptação religiosa da comunidade negra à urbanização e à industrialização. (BASTIDE, 1971, p. 302)

Tendo havido no contexto colonial brasileiro um choque civilizacional, o Candomblé que, segundo o autor, constituía-se em dependência a um modelo de socialização primária comunitária, estaria ameaçado. Daí que Bastide teria dificuldades em fornecer uma solução teórica unificada para a questão da cultura. Embora propiciando um quadro bastante diversificado, às vezes parece que no esforço etnográfico compunha a sua solução de complementariedade entre Sociologia e Antropologia oscilando justamente entre seguir o mais de perto possível a lógica produtiva oficial das representações nativas, e enfatizar os processos de transformação e recombinações nesse campo. Ao mesmo tempo, às vezes parecia que Bastide considerava demasiadamente o que diziam seus interlocutores letrados, bem como o princípio que guiava as hierarquias religiosas nos jornais da época, as quais contribuíam para a naturalização de uma lógica denominacional que se ajustasse aos pressupostos teóricos 


\section{Ciências Sociais, religião e periferia: lugares e olhares em Roger Bastide}

em que se fundavam as próprias pesquisas sobre religião de seu tempo ${ }^{6}$. Uma das causas disso diria respeito a que parte do que liam os escritores, tanto da Umbanda quanto do Candomblé, era semelhante ao que lia o próprio Bastide, gerando-se com isso uma circularidade não exatamente por tautologia, mas por ressonância. Isso era particularmente verdadeiro para alguém que procurou todo o tempo agir com extremo respeito e consideração pelo universo humano encontrado. Todavia, se não só Bastide, mas todos esses escritores rejeitavam em geral a imagem negativa que, por exemplo, muitos dos jornais forneciam indiscriminadamente em relação aos candomblés e umbandas, já não seria assim em relação à macumba, oficiantes informais e por conta própria. Dessa forma, atacandose seletivamente as representações do senso comum, muitos dos escritores participavam ativamente da confecção de um plano reclassificatório em que as diferenças entre os tipos de oficiante e de clientela passariam a ser apresentadas como uma combinação nem sempre coerente entre continuidade e ruptura, universalismo e particularismo, passado e presente. Bastide não escaparia a essa dificuldade:

É nesse sentido que o caso das 'religiões africanas no Brasil' aparece aos seus olhos [de Bastide] como uma espécie de laboratório, onde seria possível investigar empiricamente uma grande questão do pensamento sociológico. Pois se marxismo, antropologia social ou durkheiminismo concordavam, grosso modo, em atribuis à 'base'

6 Comentando sobre Herskovits, afirma Lívio Sansone: "Nessas listas [de classificação] figuravam certos termos iorubás para denotar as sacerdotisas do candomblé, que não eram utilizados então na Bahia, mas que passavam a ser de uso corrente entre os estudiosos daí por diante. Havia ainda outros termos utilizados que não eram (tão) nativos - 'religião' em vez de 'seita', 'terreiro' no lugar de 'casa'. De muitas maneiras pode-se dizer que Herskovits abraçou a missão de descrever o candomblé como uma religião propriamente dita, e não como um culto sincrético que mesclava elementos africanos com o catolicismo popular e práticas relativas ao mau-olhado, como era geralmente retratado pela imprensa local." (SANSONE, 2012, p. 18) 
uma precedência e um poder de determinação sobre as representações, o que fazer de um conjunto religioso que, ao ser arrancado literalmente à força, de sua base, em lugar de desaparecer, ao contrário, insiste em se manter? (GOLDMAN, 2011, p. 412)

Às vezes parecia que para cada expressão religiosa por ele tratada, uma hipótese distinta era sugerida para se explicar a sua especificidade dentro de uma relação nem sempre aprofundada entre passado, presente e um possível futuro. Mas como se verá, era bem mais complicado do que isso. Sugiro que, indo além não só do racialismo, mas também do culturalismo ou do antigo sincretismo, teria sido por ele considerada a possibilidade da estruturação de planos distintos de memória e validade ao seu recurso como instância fundamental de empoderamento e reprodução entre dois tipos ideais de grupos étnico-religiosos afro-brasileiros, estes, confrontados em condições concorrenciais desfavoráveis, a princípio, para ambos: os iorubás, aceitos como predominantes nos candomblés da Bahia, e os bantus das macumbas cariocas. Uma terceira formação, a Umbanda, seria justamente a síntese nacional originada no eixo Rio-São Paulo dentro da mesma corrente que daria origem ao Espiritismo kardecista e que, sob o ponto de vista do autor, estaria em melhores condições competitivas e, destarte, em vias de superar as tensões e contradições a que estariam expostos tanto o extremo comunitário sem lugar no mundo moderno do Candomblé, quanto a individualista e interesseira macumba, excessivamente promíscua e desintegrada diante do ataque modernizador.

Seguindo a corrente dominante a qual demandava por formulações valiosas à definição do nacional e, ao mesmo tempo, sem dispor de maior volume de pesquisas precedentes, principalmente históricas e etnográficas de validade regional ou local diversificadas sobre várias partes do país, a etnografia realizada pelo autor, basicamente em Salvador, combinada ao recurso a fontes secundárias teria sido insuficiente à ambição de síntese sociológica. Da mesma forma, não estavam a disposição na sua época formulações teóricas que pudessem dar um sentido de conjunto ao universo que ele tinha a frente, uma vez que seu plano de trabalho parecia bastante ambicioso. Tal universo combinava denominações convencionais e em construção com a presença de agências orientadas por um sentido predominantemente prático e não denominacional. Isso tudo diante de um 
Ciências Sociais, religião e periferia: lugares e olhares em Roger Bastide

pano de fundo católico também bastante diversificado ao longo do território e de segmentações sociais variadas.

\section{Religião, pagamento e memória}

Buscando responder a essa complexidade, enfatizaria como plano analítico a distribuição ou gradação entre padrões distintos de oficiantes, resultantes em parte de ajustamentos das práticas herdadas do XIX, em parte da relação que tais oficiantes estabeleceriam com sua clientela sob o ponto de vista da cobrança do serviço. Daí fazer todo sentido a sua opção em abordar o assunto pela perspectiva da memória. Dessa forma, ele toma como crucial a relação entre tempo e ordenamento da experiência, uma vez que condicionada por maneiras particulares de organizar e dispor objetos e recursos na extensão. Seria a partir daí que o autor abordaria o problema da economia religiosa popular, sem, contudo, nunca ter realizado uma síntese teórica abrangente ou um aprofundamento empírico sobre a questão. Nesse ponto, o enquadramento dos agentes numa zona mnemônica densa contrabalancearia as aspirações interesseiras típicas de sociedades voltadas para o lucro, tornando-se o prestígio e a consideração a principal moeda de troca entre as comunidades orgulhosas de seu passado e de sua memória coletiva. Em contraste, a ausência desse arsenal mnemônico privilegiado vulnerabilizaria em especial aqueles grupos, na verdade, meros indivíduos que, pobres de sentido, sucumbiriam rapidamente à lógica do interesse material e imediato. Vivendo-se assim num eterno presente sem significado. Daí que uma maior aproximação ou distanciamento de uma atitude individualista em que pesaria a cobrança pelos serviços prestados seria correlata a um tipo religioso em particular. Coordenação que resolveria, a princípio, a relação entre passado e futuro das expressões populares: se como fonte de lucro; ou se integrador social em forma comunitária à sociedade mais ampliada e, portanto, componente apto à preservação dos saberes. Assim, não é a Umbanda nem à Macumba que ele se dirige quando diz que: “A religião africana [...] secretou, de algum modo, como um animal vivo sua própria concha; suscitou grupos originais, ao mesmo tempo semelhantes e todavia diversos dos agrupamentos africanos. O espírito não pode viver fora da matéria e, se essa lhe falta, ela faz uma nova." Não poderia ser à Macumba porque a ela faltaria a componente grupal, já a Umbanda, seria um produto posterior e ainda em 
gestação dentro da transformação cultural nacional. Apenas ao Candomblé de matriz iorubana caberia esse privilégio.

Entretanto, Macumba e Candomblé consistiam em opções aparentemente precárias diante do desafio que ofereciam os processos combinados de diferenciação e integração classista por que passava o país. Ou seja, a solução teórica de Bastide caberia ao reconhecimento nunca equacionado da tensão entre sociedade, indivíduo e comunidade, enquanto anteparo sociológico à tensão entre universal e particular, em que as possibilidades de integração numa sociedade classista estariam constantemente ameaçadas pelas urgências materiais impostas aos grupos subalternos e empobrecidos diante de uma sociedade de classes excludente. Assim, se o candomblé se aproximaria da imagem comunitária dotada de profundo simbolismo, a macumba seria expressão do individualismo e da incapacidade do indivíduo organizar adequadamente a sua experiência senão em termos interesseiros. Já a Umbanda seria aquilo que mais se aproximaria de um sentido de sociedade como um termo intermediário que pudesse acolher aspectos do individualismo contemporâneo e, ao mesmo tempo, organizar minimamente uma experiência coletiva com o tempo e o espaço. Daí a constatação reiterada da proximidade entre crimes, violência e macumba, com a predominância das funções mágicas em que exus e pombagiras em ligação com o Diabo teriam centralidade. Essa ideia da emersão dos demônios e da magia negra em que Exu teria importância central não estava explícita em Bastide e, inclusive, ele teria procurado reabilitar o Exu do candomblé afastando-o da imagem demoníaca adquirida através dos séculos. Todavia, a velha identificação já havia sido registrada claramente em outros autores, como Arthur Ramos por exemplo ${ }^{7}$ e, como discuto em outro momento, já compunha um habitus nativo entre os praticantes dos cultos de matriz afro-brasileira:

Exu é o representante dos poderes maléficos. Entretanto, como acontece nas religiões primitivas, é objeto de um culto. Os negros brasileiros o temem e respeitam e nada fazem, nas cerimônias rituais,

\footnotetext{
7 Discuto essa questão em capítulo da minha tese de doutorado, ainda a ser defendida. Ver também: Stefania Capone em seu A busca da África no candomblé: tradição e poder no Brasil.
} 


\section{Ciências Sociais, religião e periferia: lugares e olhares em Roger Bastide}

sem o 'despacho prévio de Exu. O 'despacho' consiste de atos mágicos que provocam o 'afastamento' de Exu, para que ele não venha perturbar as cerimônias religiosas e profanas. (RAMOS, 25/5/1940, Dom Casmurro, s/n)

Essas figuras seriam associadas, especialmente por parte dos umbandistas, à macumba e a "quimbanda" tomadas como sinônimo de cultos igualmente primitivos e perigosos. Seriam também estes os termos que os umbandistas utilizaram, inicialmente, para se referir ao candomblémacumba; redutor que localizava onde estariam as reminiscências africanistas operantes no país. Outro termo que seria utilizado entre as décadas de 1920-1930 seria "linha das almas" para se falar de "magia negra". E de fato, devia ser difícil para o observador discernir naquele emaranhado de designações, o que era nativo do que seria resultante do trabalho de classificação do pesquisador.

Também para Bastide, a macumba enquanto expressão máxima de degradação mágico-religiosa em contextos de modernização, no que se valorizariam as constantes recriações nem sempre intencionais dos agentes, seria uma resultante indesejada e descartável do sincretismo típico de sociedades pós-coloniais. Nela, a cobrança pelo serviço ao priorizar o desejo pessoal de enriquecimento e empoderamento do oficiante, acabaria por subverter a lógica religiosa agindo, portanto, através da mediação monetária, como corruptora da memória coletiva e da integridade comunitária. Mais uma vez a macumba, considerada em grande parte da bibliografia das décadas 1930-1960 como predominantemente carioca, seria então a expressão mágico-religiosa mais pura de anomia social, em oposição ao candomblé, principalmente o baiano nagô; este, modelo máximo de preservação das antigas tradições iorubá. Tal oposição se tornaria o afunilador analítico a partir do qual seria resgatada a discussão sobre sincretismo em Bastide, em que os conceitos de equivalências místicas e princípios de corte seriam fundamentais.

Para tanto, o autor consideraria o sincretismo como resultante complexo de uma tripla (SILVA, 2012, p. 29) relação: estrutural, cultural e social. Estruturalmente haveria uma semelhança entre os modelos católicos e africanos em que a relação entre deuses e seres humanos seria garantida pela presença de mediadores, principalmente a Virgem Maria no 
Catolicismo e Exu no Candomblé. Culturalmente, os santos e orixás seriam agentes especializados em determinadas funções, havendo aproximação entre os conteúdos dos serviços prestados por santos e orixás. Socialmente se daria a inserção da gente de cor nas confrarias católicas em que se constituía um espaço de relativa autonomia e participação religiosa em que se teriam combinado práticas católicas e africanas. $\mathrm{O}$ que o autor não realiza é justamente o trabalho, homérico para as circunstâncias e época em que viveu, de descrever minimamente o plano em que teriam ocorrido as transformações para o padrão - ou falta deste - por ele observado no século XX. Ao colocar-se em perspectiva nacional, se tinha também que especificar a relação entre perfis distintos de impacto modernizador e localizações diferenciadas das expressões religiosas. Algo que se daria apenas mediante a quantidade e diversidade pesquisatória que começava a se publicar, excedendo-se em muito a obra de Bastide. Tornava-se urgente a profissionalização, bem como a fixação mínima de um programa de pesquisa. Coisa que começaria a ser seriamente considerada a partir das propostas de estudos sobre raça, cor e etnia, e que tinha em Arthur Ramos mediante sua presença na UNESCO, um construtor de uma rede de abrangência internacional ${ }^{8}$.

\section{Autenticidade, Bahia, cor e sociedade de classes}

Levando-se em consideração os argumentos de Bastide, a Umbanda paulista-carioca por seu turno iria na contramão do que acontecia em

8 Defendendo-se daí em diante que o Brasil era um "laboratório de civilização", pretendia-se não só chamar atenção para a necessidade de profissionalização acadêmica nacional, como mostrar o Brasil ao mundo como lugar digno de interesse em sua singularidade. Aí, não só Roger Bastide ou Arthur Ramos, mas também Edison Carneiro, Thales de Azevedo, Guerreiro Ramos, Charles Wagley, René Ribeiro, entre outros, herdeiros em parte do caminho iniciado por Nina Rodrigues, mas, inseridos num contexto político e produtivo nas ciências sociais nacionais e mundiais absolutamente distinto, encontrariam desafios e oportunidades únicas. $\mathrm{E}$ alguns desses que pretendiam aprofundar e profissionalizar os estudos sobre a cultura afro-brasileira acabaram também participando de sua construção. E antes que os institutos de pesquisa estivessem devidamente formados e em comunicação nacional e, antes mesmo que ocorresse o projeto UNESCO no Brasil, muita coisa já teria acontecido.

Latitude, Vol. 8, no 2, pp. 395-425, 2014 
Ciências Sociais, religião e periferia: lugares e olhares em Roger Bastide

Salvador. Segundo ele, a Umbanda assemelhava-se a um tipo de embranquecimento da religião, mas um embranquecimento que, embora tenha tentado ligar-se a uma origem mítica, realizava-se através da adição mais ou menos explícita de práticas advindas das mais diversas matrizes religiosas - espiritismo, candomblé-macumba, catolicismo, cultos ameríndios, religiões gregas e egípcias, persas, orientais, caboclos, enfim. Também, afirma Bastide, a Umbanda é "a valorização da macumba pelo espiritismo"; nesse caso, considerando um sentido de proletarização com o qual Ortiz não concordava, embora este concordasse com a concomitante assimilação em duas mãos entre valores cristãos-burgueses e afrobrasileiros da qual participariam segmentos sociais dominados $\mathrm{e}$ dominantes quanto as combinações entre cor e condição socioeconômica na sociedade brasileira. E se isso parecia ferir o princípio de pureza identificado ao Candomblé, seria enganoso não só considerar que o candomblé nagô não se modificava, como concluir que os indivíduos negros em Salvador eram todos praticantes e defensores dos candomblés 9 . Associado ao argumento da pureza combinava-se, entre às décadas de 1930 e 1940, mais um na defesa da tradição. E aqui, mais uma vez, Macumba, candomblés de caboclos e, em menor grau, a Umbanda, quando ligados às figuras do Caboclo e, principalmente, do Exu, com a adição de entidades ameríndias e espíritas, por exemplo, parecem importantes por razões assemelhadas, aproximando-se do discurso sobre a natureza impura da cobrança direta do serviço religioso. Bastide demonstra certa simpatia pelo Espiritismo, Umbanda, ou mesmo Candomblé de Caboclo. Todavia, sua reprovação à Macumba é absoluta. Vejamos como ele a descreve, quase sempre comparando-a ao Candomblé, Umbanda, ou Espiritismo:

O Candomblé era e permanece um meio de controle social, um instrumento de solidariedade e de comunhão; a macumba resulta no parasitismo social, na exploração desavergonhada da

\footnotetext{
9 A esse último respeito, considera Donald Pierson que os brancos pareciam mais tolerantes com os cultos afro-brasileiros na cidade que os negros dos segmentos intermediários.
} 
credulidade das classes baixas, ou no afrouxamento das tendências imorais, desde o estupro, até, frequentemente, o assassinato. (BASTIDE, 1971, p. 414)

Em comparação, a Macumba e a Umbanda:

A macumba é a expressão daquilo em que se tornam as religiões africanas no período de perda dos valores tradicionais; o espiritismo de Umbanda, ao contrário, reflete o momento da reorganização em novas bases, de acordo com os novos sedimentos dos negros proletarizados, daquilo que a macumba ainda deixou subsistir da África nativa. (BASTIDE, 1971, p. 407)

A Macumba é o que não é! Bastide não aceitava a ideia da ausência de um centro organizador que garantisse a ela um caráter de confraria ou comunidade religiosa. A existência de tal centro a impediria de mercantilizar a crença; evitaria que funcionasse como a prestadora de serviços com fins lucrativos que na verdade também era - todavia, ilícitos sob seu ponto de vista. E se na verdade esse traço não era exclusivo à macumba, inclusive pelo fato de que os iorubás também cobravam e cobram pelo serviço, o autor hesita diante de qual posição tomar. Em dado momento sugere que o caráter mais violento e consolidado da modernização carioca e paulista contribuiria para uma maior degradação religiosa; em outros, parece considerar a macumba um sistema mais frágil e incapaz de resistir por mais tempo à ocidentalização, quando comparada ao Candomblé. A macumba seria resposta disfuncional e transicional a um contexto igualmente instável entre uma sociedade de status e uma classista. Para isso, trabalha-se numa suposição que não só não é suficientemente testada por Roger Bastide, como não o seria por praticamente nenhum dos pesquisadores da religião até as décadas de 1970-1980. A de que se tratava de uma transição religiosa que acompanhava os dois tipos de sociedade, respondendo funcionalmente à mudança estrutural como um todo. Saindose de um modelo consensualmente tido como comunitário de culto regular herdado da África e adaptado à realidade colonial, isso em moldes, sob 


\section{Ciências Sociais, religião e periferia: lugares e olhares em Roger Bastide}

esse aspecto, aparentemente muito semelhantes, curiosamente, aos das religiões confessionais monoteístas ocidentais, principalmente o cristianismo, para um aberto e voltado para a sociedade classista que surgia.

Nesse aspecto em especial é necessário se enfatizar o que considero ser uma dificuldade em seu argumento. Bastide, interessado em identificar as componentes disfuncionais da macumba e sem dispor de trabalhos históricos sobre o período de transição para a República Velha e, mesmo não sendo durkheimiano, aceitaria acriticamente uma interpretação que muito se devia não só ao marco durkheimiano, como também às formas hegemônicas de representação religiosa em boa parte marcadas por uma combinação cristã-burguesa de ordenamento do sagrado. Pois, como dito, ele sabia muito bem que nos candomblés iorubás baianos também se cobrava. E, também nesse aspecto o autor não apresenta uma referência segura no passado que indicasse se tratar de um comportamento inédito da macumba como fica sugerido por sua interpretação. Enfim, ele considera que seria a injunção entre a cobrança do serviço e o não comunitarismo dos feiticeiros o que proporcionaria em particular a ocorrência de uma série de crimes, violências e abusos. E daí, pareceu natural relacionar o individualismo e economicismo da sociedade de classes com o rumo que, ao que parecia, viria tomando o seu oficiante e, portanto, a macumba, sendo essa um fator da superestrutura. Todavia, diante disso se poderia perguntar: seria a cobrança pelo serviço o que denunciaria em si mesma uma espécie de anomia, ou, a redefinição vivida pelo campo religioso, em que de fato também participava uma série de agentes e processos seculares, é que teria transformado a cobrança do oficiante espiritual em escândalo, considerando-a deturpação da autêntica religiosidade, e reclassificando, seletivamente, alguns deles para o polo inferior da magia maléfica?

De fato, Roger Bastide acabaria contribuindo para a composição da realidade a que se propôs descrever. Mas ele não foi o único dessa geração a assim agir. Vejamos. Enquanto as mães dos candomblés nagôs de Salvador, ao contrário dos mercenários macumbeiros do Rio de Janeiro, expressariam uma imagem pacificada, serena e acolhedora que em certo sentido se aproxima do ideal cristão mariano, a macumba se empobreceria ao ponto de não ser mais que estágio transitório. Passava a termo mais genérico, ao qual se somaria, ou mesmo se identificaria "quimbanda", para se designar uma miríade de expressões religiosas aproximadas a uma 
agência "mágica" - e isso ocorreria também com a colaboração dos intelectuais de Umbanda. Aderindo-se às premissas denominacionais, naturalizando-as no interior da categorização da pesquisa, convertiam-se as práticas mágicas em traços coletivos de resposta funcional, ao mesmo tempo expressão estrutural de uma determinada conjuntura que se transformava. Ironicamente, diante de tal perspectiva, fica-se tentado a colocar o próprio Bastide no interior dessa mesma tensão estrutural, nessa zona de transição entre universalismo e particularismo por que passava a nação através da geopolítica mundial, tradicionalmente centrada no poder dos antigos impérios, e talvez daí e ao mesmo tempo, a importância e a dificuldade de objetivação cultural dos subalternos que parecia ter tocado a própria sensibilidade intelectual do autor quanto à maneira como ele enxergava o seu papel no processo.

\section{Considerações finais}

Sem querer nesse momento avaliar os limites do seu prognóstico, conclui-se então que para Bastide a industrialização teria demolido o padrão estrutural que possibilitaria a manutenção de um conjunto de práticas e dependências humanas específicas e funcionalmente significativas. Foi daí que a Umbanda lhe pareceu promissora enquanto expressão popular. Ao tomá-la como possível solução ao dilema do choque entre racionalidades ou choque civilizacional, torna-se mais explícito o valor da contribuição do autor na sugestão combinada entre continuidade e ruptura religiosa, ancorada nas ideias de arranjo sincrético e capacidade humana adaptativa-inventiva no que se refere aos fenômenos da cultura. Assim, da mesma forma que as religiões africanas ao chegarem ao Brasil teriam perdido porções rituais e cognitivas, criando novos significados para algumas de suas práticas por não haver, por exemplo, a disponibilidade de sacerdotes reunidos num mesmo espaço e com locais de culto específicos, também o Candomblé, já constituído no Brasil seria essa resultante mais organizada dos ajustamentos ocorridos séculos atrás, mas que viria se reproduzindo dentro de determinado padrão já há bastante tempo.

Pode-se dizer que o esquecimento aí não diria respeito a um desgaste, espécie de corrosão natural causada pelo tempo, como se a memória oxidasse. Brasil e África também não teriam se perdido um do outro tanto pelo tempo, mas pelo lugar. Ainda que Bastide trabalhe numa perspectiva diacrônica, sua abordagem histórica é, como já sugerido, um 
tanto limitada, operando-se mais em termos de um fundo de sentido que daria unidade à sua narrativa. Assim, a riqueza do seu trabalho é devedora do imenso espaço que ganharia o problema dos fluxos humanos no interior da triangulação entre África, Europa e América. Melhor dizendo, a relação entre fluxos e configuração de uma nova civilização no contexto de modernização e formação de uma sociedade de classes. Mais uma vez, é assim que a Umbanda lhe interessará sobremaneira, inclusive porque, no seu dizer, não haveria nada de mais fascinante a um sociólogo da religião que presenciar a invenção de uma. Do mesmo modo, a corrosão das religiões tradicionais seria uma consequência segunda desse acontecimento mais fundamental, pois, ainda que oficiantes, lugares e objetos tenham se perdido durante o trânsito negro para o Brasil, esquecendo-se da existência de entidades, ritos e competências emotivas e motoras correlatas, seria o problema da incompatibilidade estrutural que imporia um processo de destruição e recriação.

Infelizmente, não é demais insistir, Bastide não realizaria de forma sistemática a necessária pesquisa histórica, como já dito, talvez impossível de ser realizada nas condições em que ele se encontrava, com o que poderia ter melhor testado suas hipóteses. Todavia, sua contribuição foi fundamental para se pensar os caminhos tomados pelas sociologias e antropologias religiosas entre nós. E, assim como vários outros intelectuais e mesmo lideranças locais, estaria ele, sob o ponto de vista do mapa mundi acadêmico que se desenhava, no interstício entre um sujeito que fala e um objeto sobre o qual se fala. Sem nunca poder encontrar um ponto ótimo de observação, mas sem nunca ter perdido certo tipo de afeto que leva a se considerar sempre haver um pouco mais para se ver.

Trate-se de acadêmicos ou não, um dos efeitos dessa circunstância é aquilo que Roberto Ventura chama de autoexotismo. Uma vez que as dificuldades na definição de quem seria esse outro da cultura nacional se embaralhavam, teve-se uma circunstância em que intelectuais locais se empenharam já na primeira metade do século $X X$ em combinação ao esforço dos estrangeiros por apresentar interpretações sobre o Brasil. Enfim, dizer que "o Brasil não é para principiantes", torna-se manifesto que atinge um duplo objetivo: por um lado, fazer-se sujeito privilegiado do discurso, por outro, não se ser seu objeto. Um jeito de sê-los sem ser com eles. Um jeito de ser conosco sem que sejam os mesmos. Entretanto, isso não impediria que figuras como Bastide rompessem o cerco de uma 
intelectualidade que por vezes agia de forma ambígua em relação às influências intelectuais "externas": ora desejosa, ora reticente em relação ao que diziam os estrangeiros. Assim também muitos dos praticantes nativos passaram a não só reelaborar a produção letrada e seu lugar nela, como a requalificarem-se mutuamente inclusive sob critérios assemelhados, mas cambiantes, de distanciamento, admiração e ingenuidade dirigidas aos estrangeiros. Havia uma sede nuca aplacada de se entrar em acordo com a "totalidade" da nação. E mesmo quando se não se tratava de artistas ou literatos, o valor da formulação intelectual, para que pudesse gerar um produto capaz de dar conta do que era fundamental e profundo em nossa cultura $^{10}$, teve de incorporar algo de estético, de contracultural, de lírico e folclórico ${ }^{11}$; de outro, os próprios agentes religiosos aproximavam-se e reelaboravam as formulações letradas a partir de suas próprias demandas, projetos e esperanças.

\section{Referências Bibliográficas}

ASAD, Talal. Religion, Nation-State, secularism. In: Nation and religion: perspectives on Europe and Asia. New Jersey: Princeton Universit Press, 1999.

BASTIDE, Roger. As religiões africanas no Brasil. São Paulo: Editora Universidade de São Paulo, 1960.

\footnotetext{
${ }^{10}$ Assim o fizeram os baianos das décadas de 1930-1940 ligados à Academia dos Rebeldes, os quais considerariam a geração modernista de 1920 como que formada por um tipo de intelectual excessivamente distanciado e afetado em sua literatura, sugerindo-se que eles não falavam com a cultura a respeito da qual falavam.

11 "Eu vim como uma pessoa que, cansada de buscar caminhos para que os homens se entendam em outros setores de atividades intelectuais, procura, no folclore, talvez um caminho mais ameno, talvez um caminho mais possível" (MEIRELES, 1950).
} 
Ciências Sociais, religião e periferia: lugares e olhares em Roger Bastide

Brasil, terra de contrastes. Tradução de Maria Isaura Pereira de Queiroz. 2. ed. São Paulo: Difusão Europeia do Livro, 1964.

O candomblé da Bahia: rito nagô. Tradução de Maria Isaura Pereira de Queiroz. São Paulo: Companhia das Letras. 2001.

O sagrado selvagem e outros ensaios. Tradução de Dorothée de Bruchard. São Paulo: Companhia das Letras, 2006.

BRAGA, Maria Lúcia. Roger Bastide e os precipícios da irracionalidade: candomblé e modernidade.VIII Congresso Luso-Afro-Brasileiro de Ciências Sociais, Coimbra, 16-18 de setembro de 2004.

BRAGA, Maria Lúcia de Santana; COSTA, Diogo Valença de A.; SOARES, Eliane Veras. O dilema racial brasileiro: de Roger Bastide a Florestan Fernandes ou da explicação teórica à proposição política. Sociedade e Cultura, v. 5, n. 1, 2007.

BURKE, Peter. Cultura popular na Idade Moderna. Tradução de Denise Bottmann. São Paulo: Companhia das Letras, 2010.

CANCLINI, Néstor García. Culturas híbridas, poderes oblíquos: estratégias para entrar e sair da modernidade. São Paulo: EDUSP, 1997.

CAPONE, Stefania. A busca da África no candomblé: tradição e poder no Brasil. Rio de Janeiro: Contra Capa e Pallas, 2009.

CARNEIRO, Edison. Candomblés da Bahia. Rio de Janeiro: Tecnoprint Gráfica S.A., 1961.

Os cultos de origem africana no Brasil. Rio de Janeiro: Biblioteca Nacional, 1959.

CAVALCANTI, Maria Laura Viveiros de Castro. Cultura popular e sensibilidade romântica: as danças dramáticas de Mário de Andrade. RBCS, v. 19, n. 54, fevereiro/ 2004. 
CHARTIER, Roger. "Cultura popular": revisitando um conceito historiográfico. Estudos Históricos, Rio de Janeiro, v. 8, n. 16, p 179-192, 1995.

ELIAS, Norbert. A sociedade dos indivíduos. Tradução de Vera Ribeiro. Rio de Janeiro: Jorge Zahar, 1994.

EISENSTADT, S. N. Modernidades múltiplas. Sociologia, Problemas e Práticas, n. 35 Oeiras abr. 2001. Sociologia, Problemas e Práticas. http://www.scielo.oces.mctes.pt/scielo.php?pid=S0873$\underline{65292001000100007 \& \text { script }=\text { sci arttext }}$

GIUMBELLI, Emerson. Religiões no Brasil nos anos 1950: processos de modernização e configuração da pluralidade. PLURA - Revista de Estudos da Religião. v. 3, n. 1, p. 79-96, 2012.

GOLDMAN, Márcio. Cavalo dos deuses: Roger Bastide e as transformações das religiões de matriz africana no Brasil. REVISTA DE ANTROPOLOGIA, SÃO PAULO, USP, 2011, V. 54 № $1 . \quad$ Fonte: http://www.revistas.usp.br/ra/article/view/38604/41451, 2011.

GUIMARÃES, Antônio Sérgio Alfredo. As elites de cor e os estudos de relações raciais. Tempo Social - Revista Sociologia, USP, São Paulo, 8 (2), outubro de 1996.

. O projeto UNESCO na Bahia. In: PEREIRA, Cláudio; SANSONE, Lívio (ORGS.). O projeto UNESCO no Brasil: textos críticos. Edufba: Salvador, 2007.

HOBSBAWM, Eric; RANGER, Terence. $A$ invenção das tradições. Tradução de Celina Cardim Cavalcante. 3. ed. Rio de Janeiro: Paz e Terra, 1997.

ISAIA, Artur César. Ordenar progredindo: a obra dos intelectuais de Umbanda no Brasil da primeira metade do século XX. Anos 90, Porto Alegre, n. 11, julho de 1999.

Latitude, Vol. 8, nº 2, pp. 395-425, 2014 


\section{Ciências Sociais, religião e periferia: lugares e olhares em Roger Bastide}

Umbanda, intelectuais e nacionalismo no Brasil. Revista de História e Estudos Culturais. Setembro/ dezembro, v. 9, ano IX, n. 3, 2012.

LANDES, Ruth. A cidade das mulheres. Tradução de Maria Lúcia Eirado Silva. 2. ed. Rio de Janeiro: UFRJ, 2002.

MAIO, Marcos Chor. O projeto UNESCO e a agenda das Ciências Sociais no Brasil dos anos 40 e 50. Revista Brasileira de Ciências Sociais, v. 14, n. 41, São Paulo, Outubro/ 1999.

MARTIN-BARBERO, Jesús. Dos meios às mediações: comunicação, cultura e hegemonia. Tradução de Ronald Polito e Sérgio Alcides. 6. ed. Rio de Janeiro: UFRJ, 2009.

NEGRÃO, Lísias Nogueira. Entre a cruz e a encruzilhada. São Paulo EDUSP, 1996.

OLIVEIRA, Olívia Fernandes de. Notas sobre algumas páginas mais ou menos modernas: o "modernismo" na Bahia através das revistas. Revista de Urbanismo e Arquitetura, v. 5, n. 1, 2008.

ORTIZ, Renato. A morte branca do feiticeiro negro: umbanda e sociedade brasileira. São Paulo: Brasiliense, 1999.

. As ciências sociais e a cultura. Tempo Social - Revista de Sociologia da USP, São Paulo, 14(1), p. 19-32, maio/ 2002.

. Românticos e folcloristas. São Paulo: Olho D'agua, s.d.

PARÉS, Luís Nicolau. O mundo atlântico e a constituição da hegemonia nagô no Candomblé baiano. 2005. Esboços-Revista do Programa de Pós-Graduação em História da UFSC, v. 17, n. 23, p. 165-186, 2010.

PECHINCHA, Mônica Thereza Soares. O Brasil no discurso da Antropologia nacional. Goiânia: Cânone Editorial, 2006. 
PEIXOTO, Fernanda Arêas. O candomblé (barroco) de Roger Bastide. Revista de Antropologia, São Paulo - USP, v. 54, n. I, 2011.

PIERSON, Donald. Brancos e pretos na Bahia: estudo de contato racial. São Paulo: Brasiliana, 1971.

PRANDI, Reginaldo. Exu, de mensageiro a Diabo: sincretismo católico e demonização do orixá Exu. Revista Usp, n. 50, 2001.

- Modernidade com feitiçaria: Candomblé e Umbanda no Brasil do século XX. Tempo Social - Revista de Sociologia da USP. São Paulo 2(1) - 49-74, 1. Semestre, 1990.

QUEIROZ, Maria Isaura Pereira. Roger Bastide, professor da Universidade de São Paulo. Estudos Avançados, vol. 8, n. 22, São Paulo. Set./Dez 1994. http://dx.doi.org/10.1590/S0103-40141994000300023.

QUERINO, Manoel. Costumes africanos no Brasil. Massangana: 1988.

RAMOS, Arthur. Macumba: religião e ritual dos negros brasileiros. Dom Casmurro, Rio de Janeiro, 1940.

O negro brasileiro: etnografia e psicanálise. Revista latinoamericana de psicologia fundamental. v. 10, n. 4, São Paulo, dez/ 2007.

. O negro na civilização brasileira. Rio de Janeiro: Casa do Estudante do Brasil, 1971.

RODRIGUES, Raymundo Nina. Animismo fetichista dos negros baianos. Rio de Janeiro: Civilização Brasileira, 1935.

- Os africanos no Brasil. Rio de Janeiro: Centro Edelstein de Pesquisas Sociais, 2010.

SANSONE. Livio. Estados Unidos e Brasil no Gantois: o poder e a origem transnacional dos estudos afro-brasileiros. RBCS, vol.27, n. 79, junho/ 2012.

Latitude, Vol. 8, no 2, pp. 395-425, 2014 
Ciências Sociais, religião e periferia: lugares e olhares em Roger Bastide

SILVA, Luís Cláudio Barroca da. "Equivalências místicas, princípio de corte e discurso colonial": ensaio de interpretação sobre a reestruturação das religiões africanas no Brasil pela ótica de Roger Bastide e Homi Bhabha. Parelellus, Recife, ano 3, n. 5, jan/ jun, p. 21-40, 2012.

SIQUEIRA, José Jorge. Os congressos afro-brasileiros de 1934 e 1937 face ao I Congresso do Negro Brasileiro de 1950: rupturas e impasses. Augustus, Rio de Janeiro, v. 10, n. 21, jul/ dez 2005.

VELHO, Otávio. Besta-Fera: recriação do mundo. Rio de janeiro: Relume Dumará, 1995.

Enviado:

15.11.2014

Aprovado:

17.12.2014 